\title{
Childhood asthma and fruit consumption
}

\author{
B.J. Okoko, P.G. Burney, R.B. Newson, J.F. Potts and S.O. Shaheen
}

ABSTRACT: The present authors investigated whether wheezing is less common in children who consume more apples and other fruits.

A population-based survey of 2,640 primary school children aged 5-10 yrs was carried out in Greenwich (South London, UK). Information about asthma symptoms and fruit consumption was obtained by means of a questionnaire.

After controlling for potential confounding variables, eating bananas at least once a day (compared with less than once a month) was negatively associated with current wheeze (odds ratio 0.66 ; $95 \%$ confidence interval $0.44-1.00)$ and ever wheeze $(0.69(0.50-0.95))$, but not with ever asthma $(0.80(0.56-1.14))$. Drinking apple juice from concentrate at least once a day (compared with less than once a month) was also negatively associated with current wheeze (0.53 (0.34-0.83)), weakly associated with ever wheeze $(0.74(-0.54-1.02))$, but not associated with ever asthma. Consumption of apples, other fruits and orange juice was not significantly associated with asthma symptoms.

No association was found between eating fresh apples and asthma symptoms in the study population, but some evidence was found to suggest that a higher consumption of apple juice from concentrate and bananas may protect against wheezing in children.

\section{KEYWORDS: Apples, childhood asthma, fruit, South London, wheeze}

$\mathrm{T}$ he increase in incidence, prevalence and associated medical and economic costs of asthma among children is a worldwide concern [1, 2]. Repeat surveys in the UK have shown that the prevalence of current wheezing and diagnosed asthma in children is still high [3, 4]. It has been suggested that the rise in asthma may partly reflect changes in the population susceptibility resulting from alterations in diet, especially a fall in antioxidant intake, rather than increasing environmental toxicity [5]. A number of observational studies in adults have found an association between low fruit intake and asthma or lower lung function [6-11].

The present authors' group has reported evidence for a protective effect of apple intake on adult asthma in Greenwich (London, UK) [8] and other communities in South East London [12]. Several other studies in children have observed similar beneficial relationships between a higher fruit intake and improvement in lung function, but not asthma symptoms [13-17]. The relationship between consumption of apples and other fruits and prevalence of wheeze was examined in a cross-sectional survey of young children attending primary schools in Greenwich.

\section{METHODS}

\section{Design}

All 64 schools included in the 2004/2005 Greenwich Primary schools list were invited to participate in the present cross-sectional study. These comprised 46 community and 18 voluntary aided schools spread over the London Boroughs of Greenwich and Bromley. Of these, 36 (56.3\%) centres agreed to participate. Invitation letters and information sheets explaining the study in more detail were sent to parents or carers of 5-10yr-old children (school years 2-5) in April 2005.

Data on asthma symptoms were collected by structured questionnaires, which were completed by parents and returned via the children's schools between April and June 2005. The questionnaire comprised sections on asthma symptoms and risk factors for childhood asthma. The asthma screening questions were based on the International Study of Asthma and Allergies in Childhood (ISAAC) [18].

\section{Definition of outcomes}

Primary outcome measures were defined as follows. 1) Current wheeze: answered yes to the question "Has your child had wheezing or whistling in the chest in the last 12 months?" 2) Ever wheeze: answered yes to the question "Has your child ever had wheezing or whistling in the chest at any time in the past?" 3) Ever-asthma: answered yes to the question "Has your child ever had asthma?"

Secondary outcomes included exercise-related wheeze, sleep disturbance due to wheeze and nocturnal cough.
AFFILIATIONS

Respiratory Epidemiology and Public Health Group, National Heart and Lung Institute, Imperial College, London, UK.

CORRESPONDENCE

P.G. Burney

Respiratory Epidemiology and Public Health Group

National Heart and Lung Institute

Imperial College London

Emmanuel Kaye Building

Manresa Road

London SW3 6LR

UK

Fax: 442073518322

E-mail: p.burney@imperial.ac.uk

Received:

July 262006

Accepted after revision:

January 242007

SUPPORT STATEMENT

The present study was funded by the UK Department of Health (London, UK).

STATEMENT OF INTEREST

None declared. 


\section{Definition of nutritional exposures: assessment of fruit intake} Consumption of apples and other fruits in the previous 12 months was assessed using a fruit frequency questionnaire. Based on previous studies [19, 20], which had shown that food frequency measures are sensitive, a set of relevant questions were extracted from a food frequency questionnaire used previously by the present authors' group [8]. Questions were asked to determine the intake of fresh apples, apple juice, bananas and other types of fruit. Secondary exposures of interest included soft, stoned, citrus, tinned and tropical fruit grouped together as miscellaneous fruit. Parents were asked to report how often, on average, their children had consumed specific fruit or juices during the previous 12 months. Questions regarding consumption of apple juice distinguished between three types: freshly prepared apple juice, juice from concentrate and any other apple juice. For each fruit or juice type, eight possible responses were available: more than once a day; once per day; 5-6 times per week; 2-4 times per week; once a week; 1-3 times per month; less than once per month; and never. Estimates of daily consumption of these fruits were then calculated as described by CAREY et al. [21]. To avoid baseline groups $<10 \%$ and other small categories, the groups were aggregated as follows: 1) consumption of fruit or juice less than once per month; 2 ) once per month to once per week; 3) 2-6 times per week; and 4) at least once per day.

\section{Analysis}

Logistic regression analysis was used to evaluate the association between asthma symptoms and fruit consumption (in four levels, using "less than once per month or never" as reference) after controlling for potential confounding variables.

\section{Adjustment for confounders}

For each fruit exposure (apples per day, pears per day, bananas per day, miscellaneous fruit per day, apple juice from concentrate per day, other apple juice per day, orange juice from concentrate per day, other orange juice/squash per day), a propensity score was defined $[22,23]$ based on the following confounders. 1) Sex. 2) Age group: 5-6, 7, 8, 9, 10-11 yrs or unknown. 3) Paracetamol exposure group: less than once per week, more than once per week or unknown. 4) Ibuprofen exposure group: less than once per week, more than once per week or unknown. 5) Vitamin, iron or other supplement use: no, yes or unknown. 6) Ever lived on a farm: yes, no or unknown. 7) Mould or mildew in bedroom: no, yes or unknown. 8) Mould or mildew in living areas: no, yes or unknown. 9) Mould/mildew in hallways: no, yes or unknown. 10) Mould or mildew in kitchen: no, yes or unknown. 11) Finance source for home repairs: family, landlord, housing association, council or unknown. 12) Current exposure to passive smoking: no, yes or unknown. 13) Ever exposed to passive smoking: no, yes or unknown. 14) Ethnic group: White British, Black British, Black African, Black Caribbean, AsianBritish, Asian, other European, other or unknown. 15) Birth weight group $(\mathrm{kg})$ : $<2.5, \geqslant 2.5-3, \geqslant 3-3.5, \geqslant 3.5-4, \geqslant 4-4.5$, $\geqslant 4.5$ or unknown. 16) Breastfeeding: no, yes or unknown. 17) Number of parents living with child: 1, 2 or unknown. 18) Number of other children at home: $0,1,2,3, \geqslant 4$ or unknown. 19) Mother's educational level: primary school, secondary school, A levels, university, post-graduate or unknown. 20)
Father's educational level: primary school, secondary school, A levels, university, post-graduate or unknown.

The propensity score for each exposure was defined using a regression model of the exposure with respect to all the confounders, which was a generalised linear model with a $\gamma$ variance function and an inverse link for miscellaneous fruit per day, and an ordinal logistic regression model for all other exposures. The values of each propensity score were grouped into 20 equal-propensity groups. For each outcome and exposure, the present authors fitted the parameters of four logistic regression models, these were: an unadjusted per-unit model, containing a baseline odds for zero exposure and an odds ratio (OR) per unit exposure; a propensity-adjusted perunit model, containing a baseline odds for zero exposure in each of the 20 propensity groups and a common per-unit OR; an unadjusted grouped model, containing a baseline odds for zero exposure and an OR for each nonzero exposure group; and a propensity-adjusted grouped model, containing a baseline odds for zero exposure in each of the 20 propensity groups and an OR for each nonzero exposure group.

\section{Ethics}

Ethical approval was obtained from Bexley and Greenwich Local Research Ethics Committee. Headteachers of all participating schools also approved the survey.

\section{RESULTS}

The parents of 5,470 primary school children were sent questionnaires to complete. A total of 2,640 (48.3\%) responded and returned completed questionnaires. Five of these children, whose ages and sex could not be determined, were removed from the analysis.

\section{Asthma symptoms}

Current wheeze was reported in 314 (11.9\%) children, ever wheeze in $24.5 \%$ and a history of ever having asthma in $18 \%$. Exercise-induced wheeze was reported in $7.8 \%$ of children and $9 \%$ of all children were reported as having both ever-asthma and current wheeze. Overall, $4 \%$ of the study population reported wheeze at least once a month and $2.6 \%$ had sleep disturbance on one or more nights per week in the previous 12 months. Of those with current wheeze, 207 (66\%) wheezed only three or less times in the preceding year.

\section{Onset of asthma symptoms}

A total of $51.5 \%$ of those with a history of asthma symptoms had their first asthma symptoms in infancy, $40 \%$ at $1-5$ yrs of age and $8.5 \%$ after 5 yrs of age.

\section{Baseline characteristics}

Table 1 shows the distribution of background characteristics of children whose parents responded. The mean (range) age of pupils in the study was 8 (5-11) yrs. A total of $40 \%$ of children lived in a household where at least one adult had either smoked in the past or was currently a smoker. In univariate analyses, living with a smoker, being male and British, having a family history of asthma and lack of breastfeeding were significantly associated with a history of ever-asthma. 
TABLE 1 Distribution of baseline characteristics and their relationship to the prevalence of ever-asthma

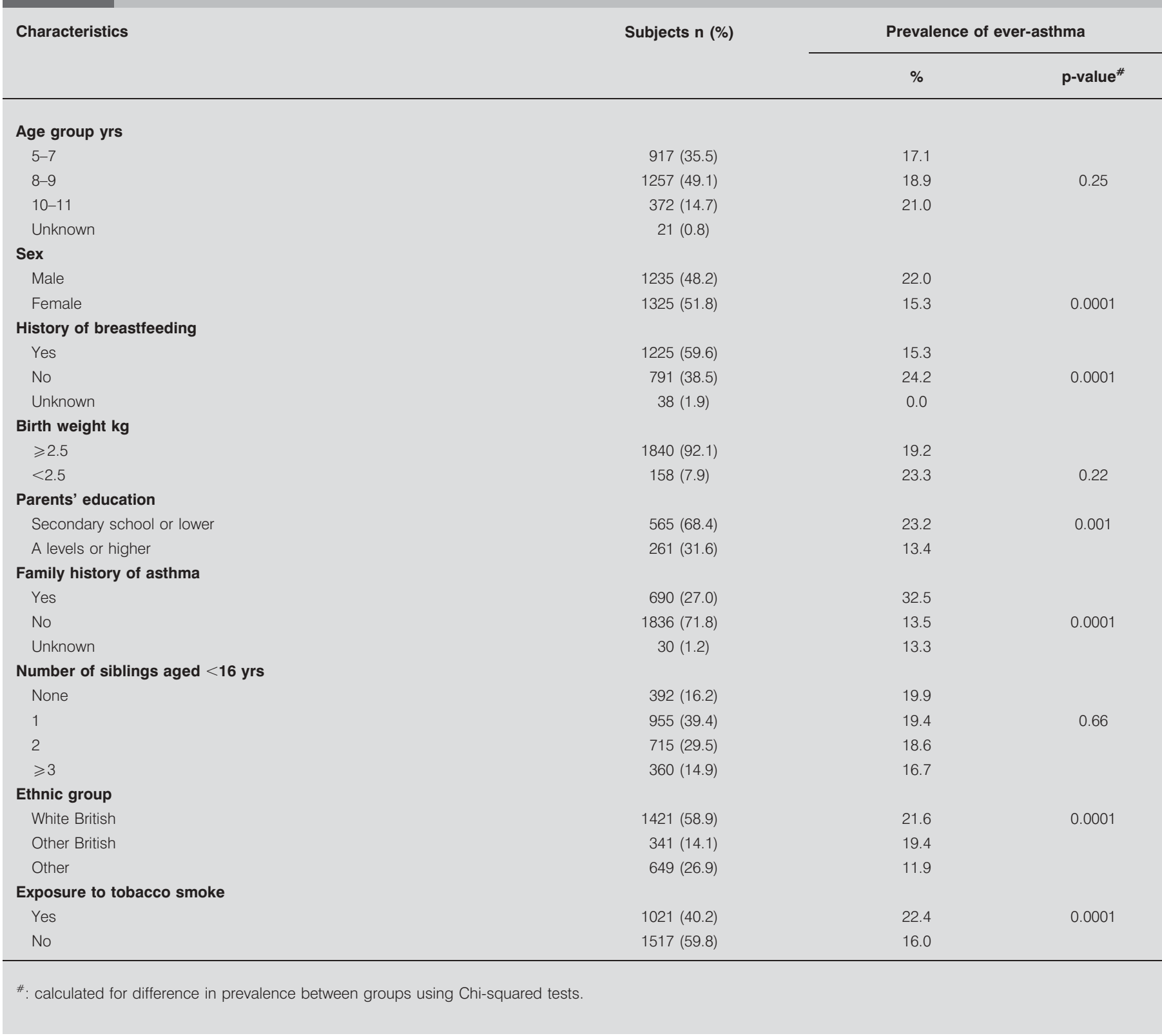

\section{Fruit eating habits}

Table 2 shows the consumption of apples, apple juice and bananas by age, sex, ethnicity and parents' educational status. There were significant differences in the proportion of children taking at least one fruit or juice serving a day between ethnic groups, sex and according to parents' educational status, but not across age groups. White British children and children whose parents had less than A-level qualifications consumed less fruit.

\section{Frequency of apple consumption}

Table 3 and figure 1 show the association between asthma symptoms and frequency of apple consumption. In univariate analyses, eating apples twice or more in a week, compared with eating them less than once a month, was negatively associated with current wheeze, ever wheeze and ever-asthma. With a propensity-adjusted model, these associations became less significant; whilst there was some evidence for a protective effect of eating apples 2-6 times per week compared with less than once a month, there was no evidence for a significant trend.

\section{Apple juice}

In a multivariate logistic regression model, apple juice from concentrate was significantly negatively associated with current wheezing and less strongly associated with ever wheezing, with evidence of a dose-response effect (table 4). There was no significant relationship between other apple (table 4) or orange juice consumption (data not shown) and asthma symptoms after controlling for confounders. 
TABLE 2 Fruit consumption by age, sex, ethnicity and parents' educational status

\section{Baseline}

characteristics

Fruit consumed

\begin{tabular}{|c|c|c|c|c|c|}
\hline \multicolumn{2}{|c|}{ Fresh apple } & \multicolumn{2}{|c|}{ Apple juice } & \multicolumn{2}{|c|}{ Banana } \\
\hline Subjects $\mathrm{n}$ & FS per day $\%$ & Subjects n & JS per day \% & Subjects $n$ & FS per day $\%$ \\
\hline
\end{tabular}

\section{Sex}

Male

Female

p-value ${ }^{\#}$

\section{Ethnic group}

White British

Other British

Other

p-value ${ }^{\#}$

\section{Parents' educational}

\section{status}

Less than A level

A level and above

p-value ${ }^{\#}$

Age group yrs

5-6

7

8

9

10-11

p-value ${ }^{\#}$
1239

1328

1439

344

639

1300

1267

258

657

659

600

374
0.04

$317(25.6)$
$351(26.4)$
0.04

349 (24.3)

$90(26.2)$

$187(29.3)$

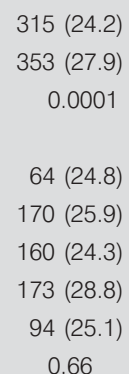

1215

1305

315

310

592

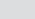

1277

1248

239

597

603

546

346

$263(21.7)$
$287(22.0)$
0.73
$71(5.4)$
$42(13.6)$
$52(8.8)$
0.0001

$214(16.8)$
$337(27.0)$
0.001
$11(4.6)$
$56(9.4)$
$47(7.8)$
$38(7.0)$
$35(10.1)$
0.46

1232

1313

1434

339

628

0001
217 (17.6)

217 (16.5)

0.81

185 (12.9)

66 (19.5)

146 (23.3)

0.0001

$200(15.4)$

234 (18.7)

0.03

41 (16.0)

$116(18.0)$

106 (16.3)

$104(17.4)$

61 (16.4)

0.58

Data are presented as $n$ (\%), unless otherwise stated. FS: fruit serving; JS: juice serving. The daily fruit and juice serving represent the proportions of children having at least one fruit or juice serving a day, respectively. ${ }^{*}$ : calculated using Pearson Chi-squared tests.

TABLE 3 Odds ratio (OR) for children's asthma symptoms associated with frequency of apple intake

Outcome

Frequency of apple consumption

\begin{tabular}{|c|c|c|}
\hline \multirow[t]{5}{*}{ Current wheeze } & $<1$ serving per month" & 16 \\
\hline & $\begin{array}{c}1 \text { serving per month-1 serving per } \\
\text { week }\end{array}$ & 61 \\
\hline & 2-6 servings per week & $10 s$ \\
\hline & $>1$ serving per day & 6 \\
\hline & $\mathrm{p}$-value for trend & \\
\hline \multirow[t]{5}{*}{ Ever wheeze } & $<1$ serving per month" & 16 \\
\hline & $\begin{array}{c}1 \text { serving per month-1 serving per } \\
\text { week }\end{array}$ & \\
\hline & 2-6 servings per week & $10 s$ \\
\hline & $>1$ serving per day & \\
\hline & $\mathrm{p}$-value for trend & \\
\hline \multirow[t]{6}{*}{ Ever-asthma } & $<1$ serving per month" & 16 \\
\hline & 1 serving per month-1 serving per & \\
\hline & week & \\
\hline & 2-6 servings per week & 108 \\
\hline & $>1$ serving per day & \\
\hline & $\mathrm{p}$-value for trend & \\
\hline
\end{tabular}

OR (95\% Cl) and significance level

ubjects $n$

165

615

1090

646

165

616

1092

651

163

606

1081

644
Unadjusted

1

$0.82(0.51-1.33)$

$0.62(0.39-0.98)$

$0.77(0.47-1.24)$

0.66

1

$0.81(0.56-1.17)$

$0.62(0.44-0.89)$

$0.68(0.47-0.99)$

0.05

1

$0.83(0.56-1.24)$

$0.50(0.34-0.74)$

$0.69(0.46-1.03)$

0.07
Adjusted

$0.82(0.51-1.33)$

$0.64(0.40-1.02)$

$0.83(0.50-1.36)$

0.91

1

$0.82(0.56-1.20)$

$0.68(0.47-0.98)$

$0.78(0.53-1.15)$

0.37

1

$0.84(0.56-1.26)$

$0.54(0.36-0.81)$

$0.79(0.52-1.20)$

0.39

$\mathrm{Cl}$ : confidence interval. ${ }^{*}$ : reference group. 
a)

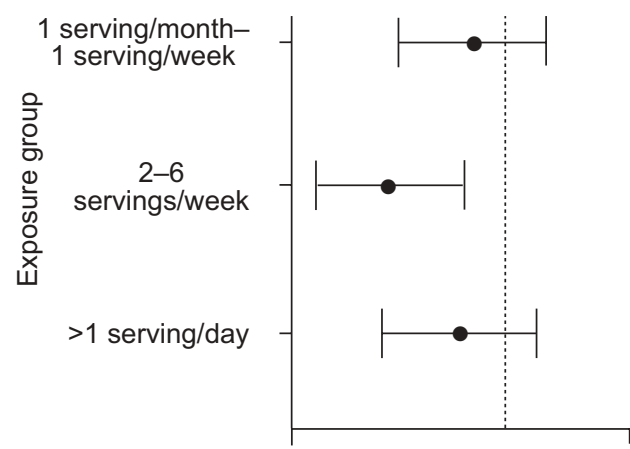

e)

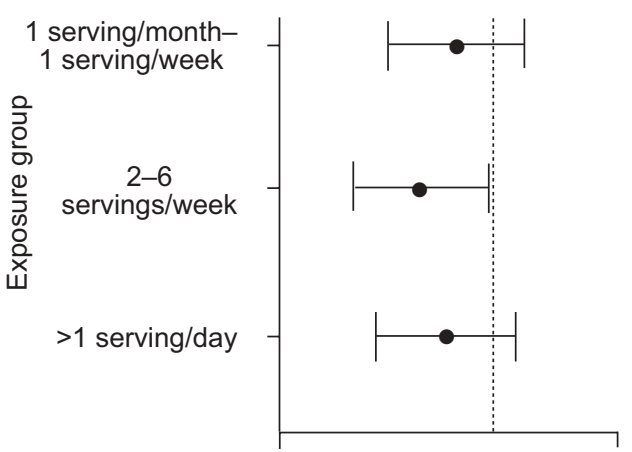

i)

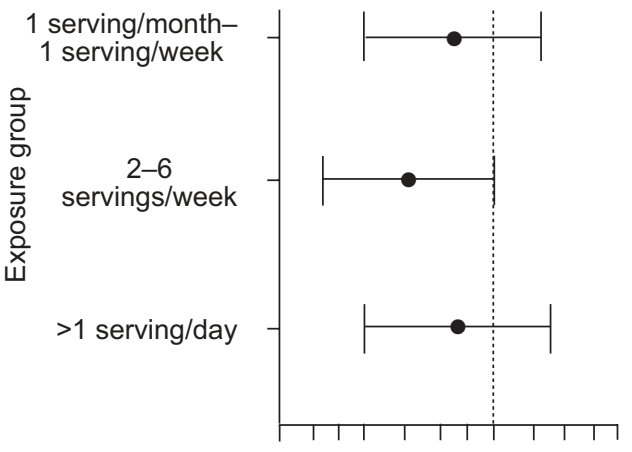

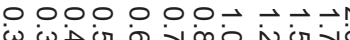

w.

Apples b)

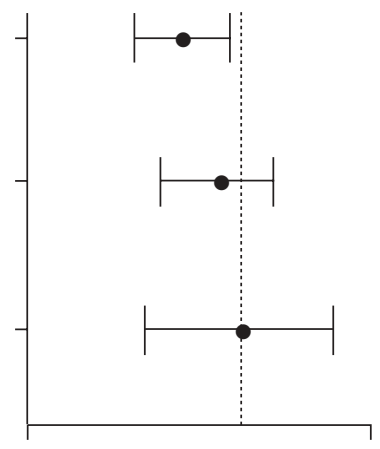

f)

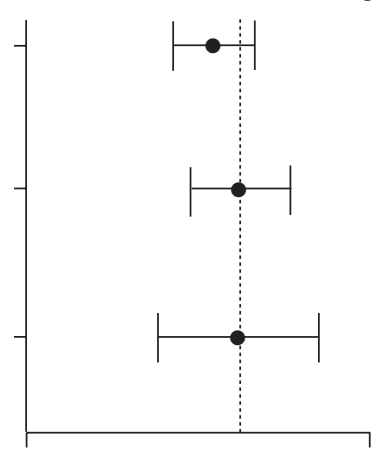

j)

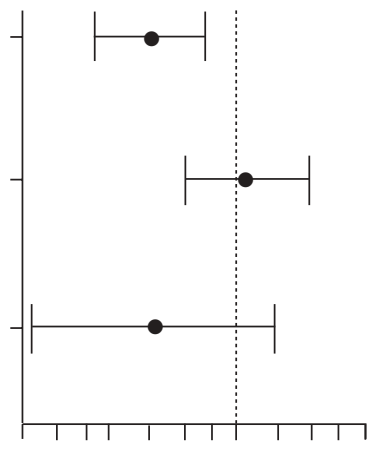

c)

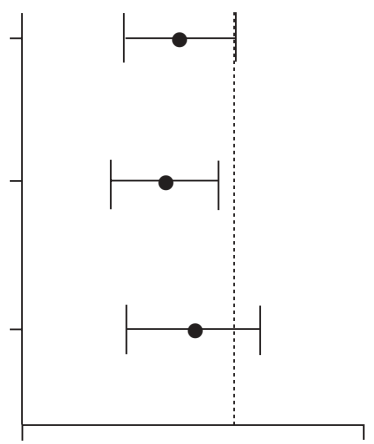

g)

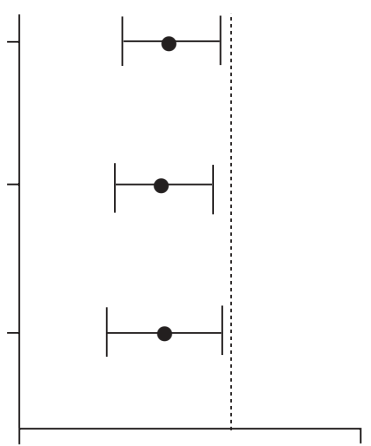

k)
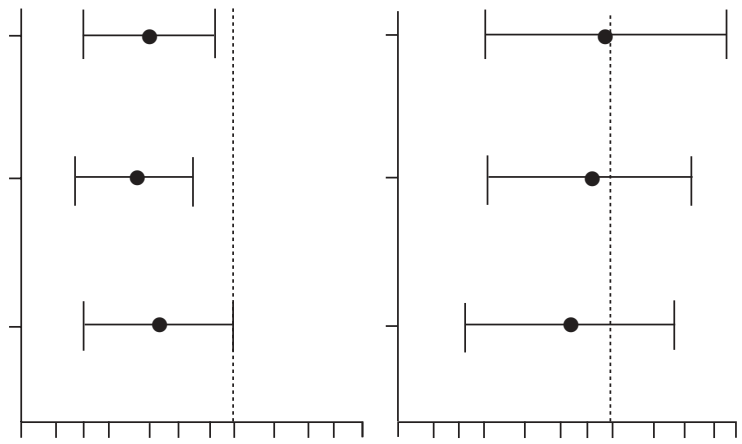

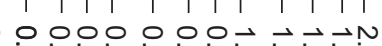

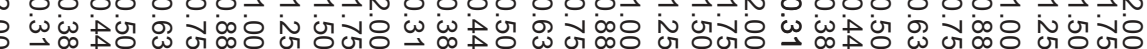

Pears

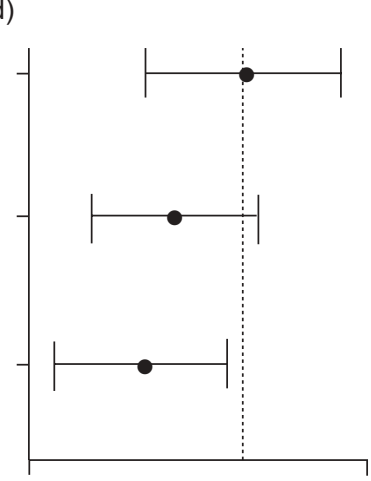

h)

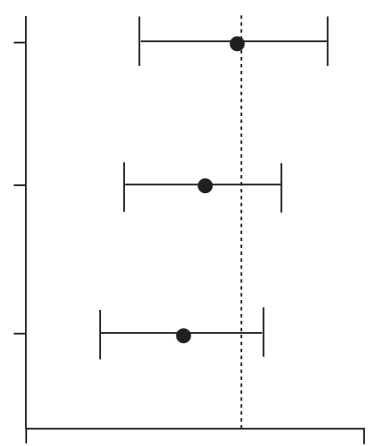

)

Grouped adjusted OR $(95 \% \mathrm{Cl})$

Miscellaneous

fruits

FIGURE 1. Plot of group adjusted odds ratios (OR) for asthma symptoms by frequency of consumption of apples, pears, bananas and miscellaneous fruits. a-d) ever had asthma, e-h) ever wheezed, i-l) current wheeze. Cl: confidence interval. ${ }^{\#}$ : the reference group had less than one serving per month.

\section{Other fruits}

Further analysis of other fruits (pears, bananas and miscellaneous fruits) showed that intake of bananas, but not other fruits, was negatively associated with ever wheeze and current wheeze (fig. 1). There was a weak association with everasthma. However, there was no evidence of a dose-response effect. Analysis of intake of fruits as a continuous variable (per portion per day) showed no significant associations with asthma symptoms. The continuous adjusted OR (95\% confidence interval) for miscellaneous fruits $(0.94(0.80-1.0))$, pears (0.89 (0.54-1.45)) and bananas (0.85 (0.58-1.24)) showed no significant protective effects against current wheeze. Similarly, there were no significant continuous effects for any of the fruits on ever wheeze or ever-asthma (data not shown).

\section{DISCUSSION}

A relationship has not been found between apple intake and asthma in the present cross-sectional study in children. However, there is some evidence to suggest that children who have a higher consumption of apple juice from concentrate and bananas exhibit a lower prevalence of current wheeze than children with a lower intake.

In contrast to studies in adults $[8,9]$, the present authors have not been able to replicate a significant negative association 


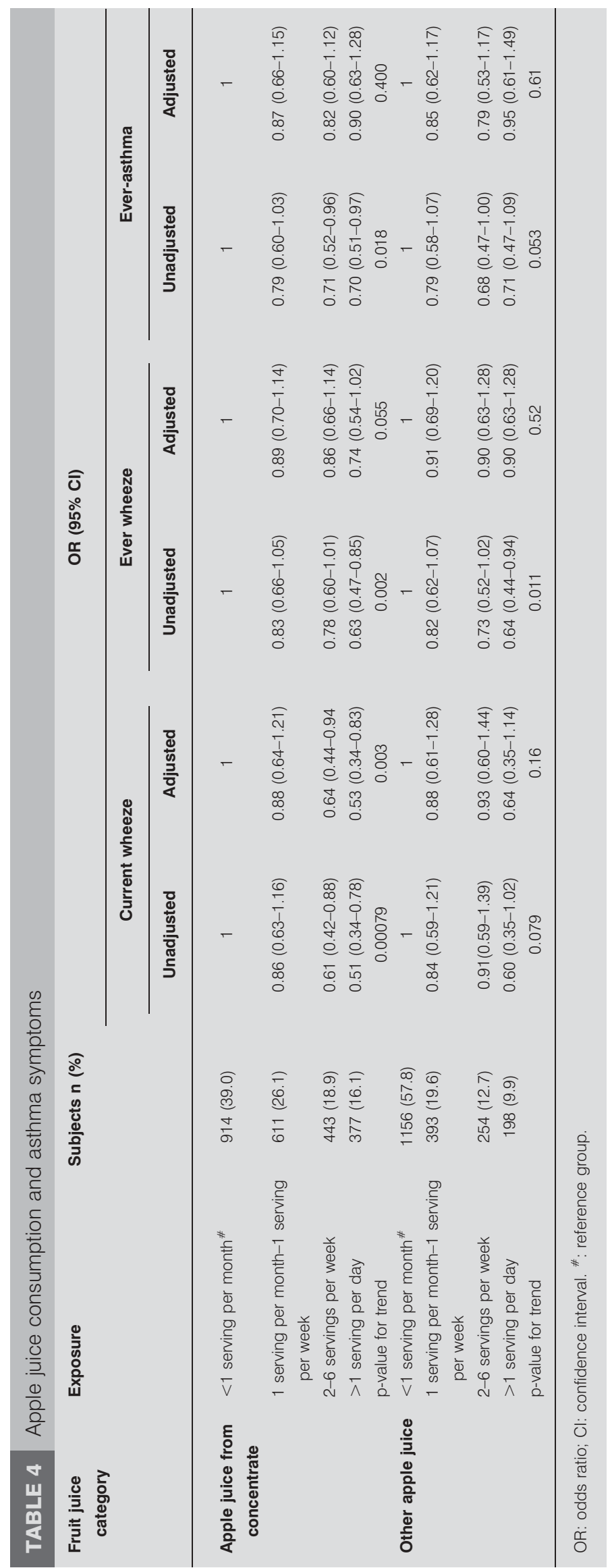

between apple intake and asthma in children. However, the present negative findings are consistent with previous studies [13-15], which showed no clear relationship between wheezing in children and fresh fruit intake despite a beneficial effect on lung function. It is not clear why the link observed in adult asthma was not replicated in children. The variation in the choice of outcome measures between studies and in the validity and reliability of food frequency questionnaires in children might have been responsible for the differences observed. Although the use of similar questionnaires to collect data on dietary items was considered to be a sensitive method in previous studies $[19,20]$, none was validated in children. It is possible that the bluntness of the fruit frequency questionnaire caused misclassification. This is especially likely in school age pupils in whom parents might not be able to account fully for fruit intake during school hours. It is also possible that the mild nature of disease in the population studied could have obscured or affected any relationship between fruit eating and asthma symptoms. Furthermore, the low response rate in the present study could have biased the results obtained and since no information is available on the difference between responders and nonresponders, the direction and extent of such bias is uncertain.

The present study observed that consumption of apple juice from concentrate was negatively associated with prevalence of current wheeze. Whilst this association may have occurred by chance, the strong dose-response relationship with current wheeze and the weaker association with ever wheeze favour a causal interpretation. Much of the protective effect of apples has previously been attributed to phytochemicals, which include flavonoids, isoflavonoids and phenolic acids [24, 25]. In fact, apples are the largest source of free phenolic acids in people's diet in the USA and Europe [26-29]. Thus, flavonoids in apples and apple juice could plausibly reduce asthma inflammation and consequently lead to improvement in disease severity [8]. However, if this were the case, it is unclear why high consumption of fresh apples was not also negatively associated with asthma symptoms in the present population. The current authors had expected to see a stronger effect of fresh fruit intake than juice consumption, as studies $[26,29]$ have suggested that the processing of apples for juice results in a very significant decrease in phenolic acids. However, a recent study [30] has suggested that the increase in plasma antioxidant capacity after apple consumption may be attributable to an increase in urate, rather than applederived antioxidant flavonoids, which tend to be poorly absorbed.

This survey incidentally found that banana intake might be beneficial for asthma symptoms. Bananas have long been recognised for their health benefit. For example, a recent study suggested an inverse relationship between cancer and banana intake [31, 32], but the present study is the first to show a link between wheeze and intake of bananas in young children, although a clear dose-response relationship was not observed. One explanation for this link might be their antioxidant content. Bananas have a higher content of water soluble phenolic acids than other fruits, including apples [31], and could plausibly reduce asthma inflammation. Furthermore, bananas have been shown to increase the absorption of other nutrients and are rich in pro-vitamin A carotenoids, which 
have been shown to protect against some chronic diseases [33, 34]. Additionally, they are one of the best sources of potassium [35], which has been reported to be negatively related to lung volumes and flows in children [36].

Although the present authors have controlled as rigorously as possible for potential non-nutritional confounders using propensity scores, the possibility of residual confounding cannot be excluded. Furthermore, some potential confounders, such as body mass index and other foods and nutrients, were not measured in the present study.

In conclusion, the present authors were unable to show a link between eating fresh apples and asthma symptoms in a population of young children. Further studies are needed to confirm the protective effects of apple juice from concentrate and bananas observed in the present study.

\section{ACKNOWLEDGEMENTS}

The authors would like to thank A. Wong and M. Tumilty for carrying out the fieldwork, and S. Chinn, R. Rona and D. Jarvis for their inputs at different stages of the present study. The authors are also grateful to the heads of the schools, parents and children that participated in the survey.

\section{REFERENCES}

1 Worldwide variation in prevalence of symptoms of asthma, allergic rhinoconjunctivitis, and atopic eczema: ISAAC. The International study of Asthma and Allergies in Childhood (ISAAC) Steering Committee. Lancet 1998; 351: 1225-1232.

2 Butland BK, Strachan DP, Crawley-Boevey EE, Anderson HR. Childhood asthma in South London: trends in prevalence and use of medical services 1991-2002. Thorax 2006; 61: 383-387.

3 Kaur B, Anderson HR, Austin J, et al. Prevalence of asthma symptoms, diagnosis, and treatment in 12-14 year old children across Great Britain (international study of asthma and allergies in childhood, ISAAC UK). BMJ 1998; 316: 118-124.

4 Anderson HR, Ruggles R, Strachan DP, et al. Trends in prevalence of symptoms of asthma, hay fever, and eczema in 12-14 year olds in the British Isles, 1995-2002: questionnaire survey. BMJ 2004; 328: 1052-1053.

5 Seaton A, Godden DJ, Brown K. Increase in asthma: a more toxic environment or a more susceptible population? Thorax 1994; 49: 171-174.

6 McKeever TM, Britton J. Diet and asthma. Am J Respir Crit Care Med 2004; 170: 725-729.

7 Devereux G, Seaton A., Diet as a risk factor for atopy and asthma. J Allergy Clin Immunol 2005; 115: 1109-1117.

8 Shaheen SO, Sterne JA, Thompson RL, Songhurst CE, Margetts BM, Burney PG. Dietary antioxidants and asthma in adults: population-based case-control study. Am J Respir Crit Care Med 2001; 164: 1823-1828.

9 Woods RK, Walters EH, Raven JM, et al. Food and nutrient intakes and asthma risk in young adults. Am J Clin Nutr 2003; 78: 414-421.

10 Knekt $\mathrm{P}$, Kumpulainen J, Järvinen R, et al. Flavonoid intake and risk of chronic diseases. Am J Clin Nutr 2002; 76: 560-568.
11 Butland BK, Strachan DP, Anderson HR. Fresh fruit intake and asthma symptoms in young British adults: confounding or effect modification by smoking? Eur Respir J 1999; 13: 744-750.

12 Sporik R, Phillips J, Potts J, Shaheen S, Burney P. Apple intake, paracetamol (acetaminophen) use and adult asthma. Eur Respir J 2003; 22: Suppl. 45, 16 S.

13 Gilliland FD, Berhane KT, Li YF, Gauderman WJ, McConnell R, Peters J. Children's lung function and antioxidant vitamin, fruit, juice, and vegetable intake. Am J Epidemiol 2003; 158: 576-584.

14 Lewis SA, Antoniak M, Venn AJ, et al. Secondhand smoke, dietary fruit intake, road traffic exposures, and the prevalence of asthma: a cross-sectional study in young children. Am J Epidemiol 2005; 161: 406-411.

15 Cook DG, Carey IM, Whincup PH, et al. Effect of fresh fruit consumption on lung function and wheeze in children. Thorax 1997; 52: 628-633.

16 Wong GW, Ko FW, Hui DS, et al. Factors associated with difference in prevalence of asthma in children from three cities in China: multicentre epidemiological survey. BMJ 2004; 329: 486.

17 Forastiere F, Pistelli R, Sestini P, et al. Consumption of fresh fruit rich in vitamin $\mathrm{C}$ and wheezing symptoms in children. SIDRIA Collaborative Group, Italy (Italian Studies on Respiratory Disorders in Children and the Environment). Thorax 2000; 55: 283-288.

18 Asher MI, Keil U, Anderson HR, et al. International study of asthma and allergies in childhood (ISAAC): rationale and methods. Eur Respir J 1995; 8: 483-491.

19 Byers T, Trieber F, Gunter E, et al. The accuracy of parental reports of their children's intake of fruits and vegetables: validation of the food frequency questionnaire with serum levels of carotenoids and vitamins C, A, and E. Epidemiology 1993; 4: 350-355.

$20 \mathrm{Hu}$ FB, Rimm E, Smith-Warner SA, et al. Reproducibility and validity of dietary patterns assessed with a foodfrequency questionnaire. Am J Clin Nutr 1999; 69: 243-249.

21 Carey IM, Strachan DP, Cook DG. Effect of changes in fresh fruit consumption on ventilatory function in healthy British adults. Am J Respir Crit Care Med 1998; 158: 728-733.

22 Rosenbaum PR. Observational Studies. New York, Springer-Verlag, 2002.

23 Braitman LE, Rosenbaum PR. Rare outcomes, common treatments: analytic strategies using propensity scores. Ann Intern Med 2002; 137: 693-695.

24 Wolfe K, Wu X, Liu RH. Antioxidant activity of apple peels. J Agric Food Chem 2003; 51: 609-614.

25 Liu RH, Eberhardt M, Lee C. Antioxidant and antiproliferative activities of selected New York apple cultivars. New York Fruit Quarterly 2001; 9: 15-17.

$26 \mathrm{Liu}$ RH. Health benefits of fruit and vegetables are from additive and synergistic combinations of phytochemicals. Am J Clin Nutr 2003; 78: Suppl. 3, 517S-520S.

27 Boyer J, Liu RH. Apple phytochemicals and their health benefits. Nutr J 2004; 3: 1-17.

28 Eberhardt MV, Lee CY, Liu RH. Antioxidant activity of fresh apples. Nature 2000; 405: 903-904.

29 Sun J, Chu YF, Wu X, Liu RH. Antioxidant and antiproliferative activities of common fruits. J Agric Food Chem 2002; 50: 7449-7454. 
30 Lotito SB, Frei B. The increase in human plasma antioxidant capacity after apple consumption is due to the metabolic effect of fructose on urate, not apple-derived antioxidant flavonoids. Free Radic Biol Med 2004; 37: 251-258.

31 Vinson JA, Su X, Zubik L, Bose P. Phenol antioxidant quantity and quality in foods: fruits. J Agric Food Chem 2001; 49: 5315-5321.

32 Rashidkhani B, Lindblad P, Wolk A. Fruits, vegetables and risk of renal cell carcinoma: a prospective study of Swedish women. Int J Cancer 2005; 113: 451-455.

33 Cho E, Seddon JM, Rosner B, Willett WC, Hankinson SE. Prospective study of intake of fruits, vegetables, vitamins, and carotenoids and risk of age-related maculopathy. Arch Ophthalmol 2004; 122: 883-892.

34 Englberger L, Darnton-Hill I, Coyne T, Fitzgerald $\mathrm{MH}$ Marks GC. Carotenoid-rich bananas: a potential food source for alleviating vitamin A deficiency. Food Nutr Bul 2003; 24: 303-318.

35 Ensminger AH, Esminger MKJ. Food for Health: A Nutrition Encyclopedia. Clovis, Pegus Press, 1986.

36 Gilliland FD, Berhane KT, Li YF, Kim DH, Margolis HG. Dietary magnesium, potassium, sodium, and children's lung function. Am J Epidemiol 2002; 155: 125-131. 